\title{
Saberes em práticas culturais: condutas e contracondutas no campo da Matemática e da Educação Matemática
}

\author{
Alexandrina Monteiro ${ }^{1}$ \\ Jackeline Rodrigues Mendes ${ }^{2}$
}

\section{Resumo}

Esse texto tem por objetivo discutir o Campo da Etnomatemática a partir de pesquisas e estudos que mostram a diversidade de entendimento desse movimento no interior do campo da Educação Matemática. Pretendemos problematizar e analisar esse movimento numa perspectiva foucaultiana, a partir do conceito de contraconduta. A importância dessa discussão se amplia pelos usos e apropriações que são feitos por essas discussões - em especial em documentos de políticas públicas as quais tendem a desviar o foco e as ideias que transitam por esse movimento. Nossa discussão irá considerar propostas de pesquisas e estudos que se sobressaíram ao longo desse movimento que vem se fortalecendo desde a década de 1980. Nossa compressão é que sua disseminação foi ocorrendo de forma rizomática, o que nos permite compreendê-lo como um movimento múltiplo. Assim, essa discussão/apresentação pretende problematizar aspectos dessa multiplicidade de propostas por vezes antagônicas considerando o fato de sua raiz emergir no interior do campo estruturalista da Matemática.

Palavras-chave: Etnomatemática; Foucault; Contraconduta.

\section{Knowledge in cultural practices: conducts and counter-answers in the field of Mathematics and Mathematics} Education

\begin{abstract}
This text aims to discuss the Ethnomathematics field based on research and studies that show diversity of understanding of this movement within the field of Mathematics Education. We intend to problematize and analyze this movement from a Foucaultian perspective, from the concept of counterconduct. The importance of this discussion is amplified by the uses and appropriations that are made by these discussions - especially in public policy documents which tend to divert the focus and ideas that move through this movement. Our discussion will consider proposals for research and studies that have stood out throughout this movement that has been strengthening since the 1980s. Our compression is that its dissemination has occurred in a rhizomatic way, which allows us to understand it as a multiple movement. Thus, this discussion / presentation intends to problematize aspects of this multiplicity of proposals sometimes antagonistic considering the fact that its root emerges within the structuralist field of Mathematics.

Keywords: Ethnomathematics; Foucault; counterconduct.
\end{abstract}

\section{Introdução}

O Campo da Educação Matemática - hoje reconhecido e estruturado internacionalmente - na década de 1970, no Brasil, foi palco do anúncio de muitas propostas de cunho

\footnotetext{
${ }^{1}$ Faculdade de Educação da Universidade de Campinas (FE-UNICAMP), Campinas, math_ale@uol.com.br

${ }^{2}$ Faculdade de Educação da Universidade de Campinas (FE-UNICAMP), Campinas, ndanda10@gmail.com
}

Periódico Horizontes - USF - Itatiba, SP - Brasil - e019029 
metodológico/pedagógico e político. Nessa época dois acontecimentos foram fundamentais. Um deles foi a organização e oficialização da Sociedade Brasileira de Educação Matemática e a outra foi a criação do primeiro curso de Mestrado em Educação Matemática do Brasil junto ao instituto de Matemática da UNESP - Campus de Rio Claro ambos oficialmente realizados na década de 1980.

No interior dessa mobilização para o reconhecimento do campo da Educação Matemática muitas forças se cruzaram. Um dos grandes temas de disputa se centrava na dicotomia entre Educação e Matemática. Ou seja, para muitos - em especial os matemáticos - educação/ensino consistia num conjunto de técnicas didáticas que motivariam e garantiriam que alguns alunos aprendessem Matemática - já que nem todos teriam esse "dom". Para outros, a Educação tinha um papel político e nesse sentido a Matemática deveria ser ensinada como uma ferramenta para os processos revolucionários democráticos. Enfim, de um lado a outro, pensava-se em Educação Matemática (EM) como Educação + Matemática $(E+M)$, sendo ora um campo ora outro a ferramenta dos objetivos de ensino.

Dentro desse movimento de disputa uma pluralidade de propostas emergiu. Essas diferentes propostas formaram os Grupos Temáticos (GTs) ${ }^{3}$ do campo da EM como exemplo podemos citar os GTs de: Modelagem Matemática, a Etnomatemática, Filosofia da Matemática e História da Matemática, entre outros.

A Etnomatemática passa a se destacar na década de 1980 e, desde então, vem se fortalecendo. Nesse processo, muitas discussões, pesquisas e trabalhos foram realizados e publicados produzindo uma disseminação quase viral, ou melhor, dizendo: rizomática.

Desse modo, esse movimento precisa ser problematizado a partir de sua multiplicidade, de seus antagonismos e paradoxos. Assim, pretendemos interrogar algumas das suas vertentes, em especial aquelas que do nosso ponto de vista mostram-se contraditórias frente aos princípios que as mobilizaram. A conjectura que aqui defenderemos é a de que as contradições que emergem entre as diversas tendências da Etnomatemática podem ser justificadas se compreendermos esse movimento como um movimento de "contraconduta" conforme proposto por Foucault. Mas, por que nos interessa essa discussão?

\footnotetext{
${ }^{3}$ O Campo da EM está organizado atualmente em 15 GTs.
} 
Poderíamos listar muitos motivos para abordar essa temática, mas o que mais fortemente nos move nesse momento é o efeito desse movimento como uma "contraconduta" especialmente na produção de encaminhamentos pedagógicos - do nosso ponto de vista equivocados e superficiais. Tais encaminhamentos circulam por documentos oficiais o que os levam a ser considerados como verdades absolutas. Nesse sentido, entendemos que essa discussão pode auxiliar na desconstrução de uma tendência metafísica que nega as diferenças de vertentes e de filiações teóricas que podem indicar possibilidades outras para pensarmos os saberes escolares, o currículo e a própria Matemática.

\section{Etnomatemática como contraconduta}

Antes de discutirmos a Etnomatemática propriamente, faz-se necessário destacar o que estamos compreendendo por conduta e contraconduta. No curso intitulado Segurança, Território, População, realizado no ano de 1978, no Collège de France, Foucault (2008) discute, entre outras coisas, alguns tipos de governamentalidade, indicando a impossibilidade de se pensar em formas de governo dissociadas de formas de resistências. Em termos gerais, podemos dizer que os dispositivos de governamentalidade são mobilizados porque existe a possibilidade dos sujeitos se recusarem a obedecer às condutas propostas. E, é na superfície da possibilidade da recusa que emergem as crises da governamentalidade, as quais potencializam a produção de resistências ou movimentos de contraconduta.

Segundo o próprio Foucault (2008), a palavra "conduta" é ambígua pois, refere-se a duas coisas: a prática da condução, mas também à maneira como uma pessoa se deixa conduzir, o que nos remete à ideia de conduta como movimento no qual o sujeito tem a possibilidade de querer ser conduzido de outra forma. Por isso a contraconduta não é uma forma de revolta nem tão pouco uma desobediência. Foucault propõe o emprego da palavra "contraconduta", no sentido de "luta contra os procedimentos postos em prática para conduzir os outros" (p.271).

Para Candiotto (2010), o sentido atribuído por Foucault ao termo contraconduta, abre "a possibilidade (do sujeito) atuar como agente da própria subjetivação a partir de outro modo de condução que não aquele da obediência integral e incondicional" a qual está submetido (p.10). Assim os movimentos de contraconduta teriam como objetivo outra conduta, isto é: 
'Querer ser conduzido de outro modo, por outros condutores e por outros pastores, para outros objetivos e para outras formas de salvação, por meio de outros procedimentos e de outros métodos', seriam formas de 'escapar da conduta dos outros', procurando definir para cada um a maneira de se conduzir (FOUCAULT, 2008, p.287).

Diante disso, nossa proposição neste trabalho é a de que a Etnomatemática se apresenta como um movimento de contraconduta no interior do campo do saber da Matemática Acadêmica. E, alguns dos elementos principais para a emergência desse movimento foi o baixo rendimento escolar nessa disciplina em muitos países do mundo e a aproximação de alguns renomados matemáticos ao campo da Antropologia no desenvolvimento de trabalhos realizados junto a UNESCO ${ }^{4}$ em especial, no continente africano.

Esse movimento de contraconduta emerge ao se opor ao campo de racionalidade em que a Matemática se fortalece como uma metanarrativa, pensada como única e independente de qualquer contexto sociocultural. Entendemos que essa metanarrativa se organiza dentro de uma formação discursiva pautada numa racionalidade de tradição filosófica transcendental e essencialista, conforme aponta Clareto (2011):

A matemática, no mundo moderno de tradição ocidental, tem sido uma metanarrativa, uma narrativa mestra: é ela que legitima o conhecimento; é ela que coloca os parâmetros para a verdade... Ela é a 'pedra de toque específica', a pedra fundamental, o princípio unificador, o fundamento universal da verdade e das certezas. Ciência das quantidades e das regularidades, a matemática tem colocado os parâmetros de identificação do real e os parâmetros de inteligibilidade e de racionalidade (p.17).

Essa narrativa mestra que pretensiosamente legitima o conhecimento científico se estrutura a partir de regras de normas que ditam o que pode ou não fazer parte desse campo de saber. Nesse sentido, a Matemática Acadêmica é revestida de um discurso que se apoia na crença de ser algo para além da humanidade, com existência própria e, portanto, um saber a ser descoberto ou, numa outra perspectiva, se apoia em padrões, regras e princípios que devem ser seguidos com rigor para se garantir a construção de enunciados verdadeiros.

\footnotetext{
${ }^{4}$ UNESCO. Declaração Mundial sobre Educação para Todos: satisfação das necessidades básicas de aprendizagem, Jomtien, 1990. Disponível em: http://unesdoc.unesco.org/images/0010/001095/109590por.pdf. Acessado em: 19/11/2012.
} 
Essa trama articulada de regras e normas produz certa forma de pensar, e de conduzir, e se conduzir frente às questões ditas matemáticas. Enunciados, como "Matemática é única e universal", geram a crença de que uma vez que algo é provado matematicamente, esse algo, torna-se inquestionável. E, dentro desse rigor e dessa busca pela verdade, a Matemática se fortalece a partir de definições, teoremas, axiomas, enfim, dentro de uma gramática que delimita aquilo que faz ou não parte desse campo de saber. E, dentro desse campo de certezas, a pergunta "o que é" não só faz parte, como é de fundamental importância para esse universo discursivo.

No campo educacional, essa metanarrativa se converte em práticas centradas em conteúdos, normas e técnicas que permitem aos sujeitos (re)conhecerem as verdades matemáticas. Nessa perspectiva muitas propostas educacionais se voltam para questões metodológicas que facilitem a aprendizagem dos alunos sobre esses saberes.

Entretanto, os baixos resultados em Matemática entre estudantes - tanto no Brasil como em diversos outros países - levaram educadores a voltarem sua atenção aos processos educacionais e, com isso, muitas reformulações curriculares passaram a ser questionadas e/ou modificadas, e esse tema passou a fazer parte de muitos Congressos nacionais e internacionais de Matemática. Além disso, projetos financiados pela UNESCO no final da década de 70 - em especial no continente africano, buscaram melhorar os índices das avaliações matemáticas e, desse modo, financiou-se pesquisas multidisciplinares das quais participaram matemáticos, antropólogos, historiadores, linguistas. Dentre esses, destacamos o professor brasileiro, Ubiratan D'Ambrósio. Juntos, essa equipe de pesquisadores passou a discutir, especialmente, a mobilização dos saberes matemáticos em diferentes práticas culturais, produzindo novos questionamentos sobre a própria Matemática, o que resultou em novos discursos e novas propostas, como a da Etnomatemática.

O que se destaca do discurso que emerge desse lugar, denominado Etnomatemática, é que ele questiona algumas das principais estruturas do campo acadêmico da Matemática, em especial, a universalidade e seu poder de emitir verdades únicas e absolutas. Desse modo, nós entendemos, neste trabalho, que esse novo lugar se organiza a partir de outra formação discursiva que emerge dentro desse campo, apresentando-se como uma resistência aos modos de governamento (im)postos pelo campo da Matemática formal. Uma resistência que não nega 
a Matemática, tão pouco pretende instituir uma revolução nesse campo do saber, mas que intenciona alargar as compreensões a partir de outras possibilidades de se pensar sobre fazer matemática. Busca novas formas de pensar os saberes, novas condutas e normas de constituição desses, por isso, estamos aqui entendendo essa proposta como um movimento de contraconduta.

Posto de outro modo, a Etnomatemática aparece como uma contraconduta - por não romper com a estrutura da Matemática e nem mesmo colocar-se contra os princípios desse campo do saber, mas, reclama por outra forma de pensar e de se fazer Matemática. Esta outra forma emerge da dúvida e de novas questões propostas sobre a unicidade e universalidade que este campo do saber matemático se autoafirmava. Os rastros dessa contraconduta nos apontam, em especial, para experiências pautadas na alteridade cultural e social, bem como para a aproximação dos pesquisadores matemáticos a outros campos do saber, como: Antropologia, Sociologia, Linguística, História e outros mais.

Porém, a Etnomatemática, enquanto movimento de contraconduta, se deixou capturar pelo poder da Matemática, quando, mesmo se colocando como uma possibilidade de reconhecimento de um outro saber, os saberes de outras práticas foram capturados pelo discurso da Matemática, mostrando-se potencialmente menores que o saber acadêmico escolar. Diante disso, a discussão desses saberes outros têm a função de aprimorar ou garantir o poder da matemática que tudo sabe e tudo resolve.

Desse modo, o discurso etnomatemático, apesar de emergir do sufocamento que a Matemática Acadêmica provocava e ainda provoca no contexto escolar, gerando a necessidade de um grito libertador dessa estrutura totalizante, não deixa de ser capturada pela metanarrativa mestra, herdada do positivismo, da rainha das ciências.

A proposta da Etnomatemática emerge como recusa das condutas de universalidade e verdade absoluta defendida por esse campo do saber. Sem produzir um rompimento, essa recusa gera questionamentos e coloca a metanarrativa mestra em suspenso. Essa recusa conduz para outras possibilidades de se pensar, produzindo uma outra formação discursiva que atua no interior dos dispositivos de governo que se instituem no processo de garantia das condutas. Nesse sentido Orellana (2012) afirma que:

Periódico Horizontes - USF - Itatiba, SP - Brasil - e019029 
[...] os dispositivos de governamentalidade são mobilizados porque existe a possibilidade dos sujeitos se recusarem a obedecer às condutas propostas. E, é na superfície da possibilidade da recusa que emergem as crises da governamentalidade as quais potencializam a possibilidade de produção de contracondutas (p.43).

Assim, entendemos que a Etnomatemática emerge como um movimento de contraconduta ao entrar no jogo de forças para lutar contra princípios que legitimam certos procedimentos utilizados na condução dos sujeitos e das práticas do saber matemático.

Os discursos advindos desse movimento produzem efeitos no campo do saber matemático, mas atravessando de forma mais efetiva e questionadora os discursos relacionados às práticas pedagógicas da Matemática. É nesse segundo aspecto que a captura desse processo remete ao modelo estruturalista e universalista que sustenta a rainha das ciências.

Nesse sentido, ela passou a ser compreendida por uma nova metodologia de ensino e foi identificada e/ou reconhecida por produzir processos que desqualificam a formação do outro, pois, ao valorizar saberes cotidianos, ditos do senso comum, impossibilitariam estudantes de terem acesso ao saber científico e com isso minimizariam a possibilidade de esses atuarem de forma crítica na sociedade.

Em outra perspectiva, a Etnomatemática foi entendida como um espaço de resistência, mas apenas para processos educacionais não escolares. E, nesse movimento, aproximou-se de questões da História da Matemática, habitando de forma efetiva o campo da pesquisa em Educação Matemática.

A multiplicidade de discursos criados em torno da proposta da Etnomatemática gerou e ainda gera discussões e encaminhamentos, especialmente no âmbito pedagógico, que se distanciam dos fatores mobilizadores desse projeto, cujo objetivo foi de resistir às formas de pensar a ciência e, em especial, a Matemática a partir de um único modelo proposto como verdadeiro e universal. Nesse sentido, discutir a Etnomatemática hoje, nos parece exigir um movimento sobre o que os etnomatemáticos têm falado e produzido nesse campo. Posto dessa forma, a Etnomatemática pode ser entendida de diversas maneiras e pode produzir diferentes efeitos de sentido, por exemplo, no campo curricular. 


\section{Algumas considerações sobre os efeitos no campo curricular}

O discurso crítico na área de currículo, em especial no campo da Educação Matemática, vem sinalizando a necessidade de relacionar o saber escolar e não escolar, sendo este último geralmente denominado como saber cotidiano.

Muitas questões de ordem pedagógica, apresentadas numa perspectiva Etnomatemática, procuram compreender quais são as implicações das reflexões desenvolvidas por esse campo de pesquisa para a prática escolar, para o currículo e, consequentemente, problematizam o modelo atual da instituição escolar. Desse modo, os debates no campo da Etnomatemática têm envolvido discussões sobre diferença e multiculturalidade, entre outras. No campo curricular, muitos autores ${ }^{5}$ têm produzido obras que têm indicado uma tendência de propor alternativas que possam contribuir para a superação de questões que envolvam a aproximação entre saberes escolares e cotidianos.

Porém, numa outra perspectiva, entendemos que a Etnomatemática pode ser pensada para além da relação entre Matemática escolar e cotidiana. Ao tomar como foco a mobilização dos saberes dentro de diferentes práticas sociais e culturais, o que se busca é trazer para discussão práticas e saberes na perspectiva em que eles são significados, e as formas de uso a partir da ótica dos sujeitos que as realizam, e, desta maneira, buscar nas práticas e não nas disciplinas (Matemática, História, ...) os possíveis sentidos desses saberes.

Assim, quando o saber passa a ser compreendido na perspectiva das práticas as denominações disciplinares tendem a se reorganizar, a traçar novas tramas e a constituir novas formas de pensar a própria Educação. Por outro lado, esse movimento não apaga as metanarrativas disciplinares e tão pouco se pretende ser uma metanarrativa única e verdadeira, de tal modo que o movimento contrário também ocorre, ou seja, os grupos passam a chamar suas práticas de "Matemáticas". Nesse caso, Mendes (2004) discute que esse movimento nominalista da prática em disciplina tem um caráter político e simbólico que serve para fazer uma contraposição ao conhecimento do dominante no contexto de minorias, como é caso da

\footnotetext{
${ }^{5}$ Veiga-Neto (2005); Moreira e Silva (2001); Apple (1997). No campo da Educação Matemática, os trabalhos de, Monteiro e Brolezzi (2012); Bello (2010); Miguel, Vilela e Moura (2010); Mendes (2004, 2001); D’Ambrósio (2001); Monteiro (1998); Knijnik (1996), entre outros.
}

Periódico Horizontes - USF - Itatiba, SP - Brasil - e019029 
discussão apresentada por essa pesquisadora em que professores indígenas passam a fazer referência a uma "Matemática Indígena" para opor-se politicamente à Matemática do não-índio.

Enquanto ação de contraconduta, o movimento da Etnomatemática pretendeu denunciar e modificar os dispositivos que sustentavam as relações que permeiavam os processos de validação e legitimação do saber escolar. Como decorrência dessa discussão, no âmbito pedagógico, buscou-se discutir as possibilidades de articulação entre os conhecimentos produzidos em práticas culturais e o conhecimento escolar. No âmbito pedagógico diversos discursos foram produzidos, ora apontando diferenças de poder existente entre essas formas de conhecimento, ora buscando a superação de um saber sobre o outro, tendo como referência sempre a Matemática Acadêmica como aquilo que se compreendia ou denominava saber matemático.

Ao se fazer isto, tornou-se possível pensar e criar outras formas de conduta que perpassam os campos pedagógico e curricular; entretanto, em alguns casos houve um reforço do modelo universalista e totalitário, especialmente quando a diferença é pensada como modo de superação ou de uma comparação, a qual tem como referência a Matemática Acadêmica, e não como uma diferença em si mesma.

O campo de ações de contraconduta da Etnomatemática cria novas possibilidades de se pensar matematicamente, compreendendo, neste caso, os saberes como possibilidades de criação e não de reprodução, como pensamentos outros, que descartam o processo de validação dos procedimentos vinculados a um modelo tido como verdadeiro. Talvez poderíamos pensar por simulacros! Seria isso possível? Essa proposta nos parece ir além de uma contraconduta, ela não se coloca contra algo, mas, assume um algo outro, assume uma outra dinâmica, uma outra possibilidade de pensamento, proposta esta que não busca o reconhecimento, mas a criação, uma conduta outra. Caberia pensar a Etnomatemática como um conceito no sentido deleuziano? Neste caso do que se trataria?

\section{Etnomatemática: movimento ou conceito?}

Por que pensar a Etnomatemática como um movimento? Seria possível pensarmos a Etnomatemática como um conceito na perspectiva deleuziana? Para Deleuze e Guattari (1992), Periódico Horizontes - USF - Itatiba, SP - Brasil - e019029 
filosofar não é contemplar, refletir ou comunicar, para eles filosofar é uma prática de criação, de construção. É algo que precisa ser arrancado. É um grito. Para eles “todo conceito remete a um problema, a problemas sem os quais não teria sentido, e que só podem ser isolados ou compreendidos na medida de sua solução" (p.25).

Assim, poderíamos entender a Etnomatemática como um conceito que emerge na forma de um grito - neste caso o grito de uma comunidade pronunciado pelo professor Ubiratan D’Ambrosio?

Esse grito ecoa frente a um contexto em que poucos conseguiam aprender Matemática e, dessa forma, reforça-se o mito de que somente algumas mentes seriam capazes de compreender esse saber. Esse talvez seja o fator de maior indignação que se colocou e, infelizmente, ainda se coloca no contexto escolar. Como aceitar um discurso que defenda esse mito?

Desde a década de 1970, o mau desempenho dos alunos em Matemática - no mundo vem gerando indignação entre educadores, comunidade e matemáticos. Movidos pela incapacidade de aceitar os desastrosos resultados dos estudantes nas avaliações, na década de 1970, focando, em especial, no baixo rendimento dos negros americanos (EUA), um grupo de pesquisadores: matemáticos, historiadores, antropólogos, sociólogos, linguistas - financiados pela Unesco - passou a viajar pelo continente africano para tentar compreender mais esses povos e suas culturas com objetivo de buscar alguma explicação.

No decorrer dessa pesquisa, do contato com essa cultura, inicialmente sem qualquer pretensão de promover revoluções, emergiu um grito: não podemos considerar a Matemática Acadêmica ocidental como um modelo único de pensamento. Diferentes povos possuem maneiras próprias de resolver e expressar suas soluções, cujos caminhos desconsideram muitas das abordagens do modelo cientificamente aceito pelas instituições científicas e escolares.

A partir dessa experiência, o professor D’Ambrósio, que participava dessa equipe de pesquisadores, retorna ao Brasil e junto com os professores Eduardo Sebastiani e Rodney C. Bassanezzi, propõe essa discussão no IMECC-UNICAMP. Dessas discussões, eles criaram a disciplina "Matemática e Sociedade". Vale ressaltar que Ubiratan D’Ambrosio se utilizou pela primeira vez do termo Etnomatemática, em 1985, no livro Etnomathematics and its Place in the History of Mathematics, inserindo o termo no campo da História da Matemática. 
Nesse livro o autor cita que em 1978 utilizou o termo numa conferência que pronunciou na Reunião Anual da Associação Americana para o Progresso da Ciência, infelizmente não publicada. Internacionalmente esse movimento ganhou corpo a partir do International Congress on Mathematical Education (ICME), 1992, em Quebec, no qual D'Ambrosio levantou a necessidade de se buscar a homogeneização conceitual, ou uma definição de Etnomatemática, cujo termo havia sido cunhado por ele anos antes.

Desde então, são diversas as discussões e propostas que tentam explicar, expandir ou responder à questão: o que é Etnomatemática? Ao formular uma questão pelo "o que é" criouse uma expectativa de resposta explicativa, de uma definição da essência daquilo que "é" e, nesse sentido, tal pergunta originou muitas pesquisas cujos objetivos metafísicos procuravam pela essência da coisa que se diz ser o que é. Neste caso, ao propor a questão: o que é Etnomatemática?, os pesquisadores projetaram ou enquadraram o grito por uma Matemática outra na objetividade definidora da Matemática, e muitos estudiosos passaram a buscar uma identificação isomórfica entre a palavra (Etnomatemática) e a coisa (sua essência) de forma a se enquadrar dentro do campo (ideal) da Matemática.

Ao ser colocada a questão: "o que é alguma coisa", criamos uma armadilha, pois passamos a estabelecer conexões isomórficas e nos afastamos das possibilidades, das inquietudes, do desconhecido, do novo e da criação. Porém, dentro do campo da Matemática, a resistência em romper com esse tipo de questão é imensa. Nesse sentido, nos parece importante retomar Nietzsche (1981), quando este nos alerta sobre o perigo de buscar por esse caminho isomórfico quando se trata de discutir o ato de conhecer algo, segundo esse filósofo:

- Apanhei esta explicação, eu encontrei na rua; ouvi um, dentre os populares, dizer: "Ele me reconheceu"-: então me perguntei: o que entende o povo por "conhecer"? O que deseja quando quer "conhecimento"? Nada, além disto: alguma coisa estranha deve ser posta em conexão com algo conhecido. E nós, filósofos, que pretendemos entender por conhecimento? Aquilo que é conhecido, isto é, aquilo que estamos habituados, de modo que não nos espantamos mais, nosso movimento quotidiano, uma regra qualquer que nos rege, tudo que sabemos nos é familiar; como?! Nossa necessidade de conhecimento não é justamente essa necessidade do conhecido? O desejo de descobrir, entre todas as coisas estranhas, inabituais, incertas, alguma coisa que não nos inquiete mais? (NIETZSCHE, 1981, p.243).

Periódico Horizontes - USF - Itatiba, SP - Brasil - e019029 
Nietzsche nos alerta para o perigo de perdermos a sensibilidade ou o desejo por criar o novo ao limitamos nossos anseios pelo saber estabelecendo isomorfismos, ou seja, numa ação de reconhecimento na qual se procura pelo que já "é"; portanto, pelo que já está posto e conhecido. Nessa perspectiva nós não conhecemos algo, nós apenas reconhecemos. $E$, nesse sentido, o grito por outra forma de pensar a matemática passa a ser gerenciada como um movimento de contraconduta.

Por isso, Etnomatemática nos remete à imagem de movimento, pois os princípios que a sustentam e que provocaram o grito d'ambrosiano, ao serem capturados pela estrutura matemática, vai sendo associado àquilo que estamos habituados, de modo que não nos espantamos mais, [... a] uma regra qualquer que nos rege, [àquilo] que nos é familiar. Mas, por que essa captura e adequação ao familiar se tornam tão comum e resistente?

Nosso pressuposto, seguindo uma perspectiva foucaultiana, é de que essa captura e adequação da proposta da Etnomatemática a um modelo estruturalista da Matemática acadêmica/científica decorre de uma proliferação do movimento de contraconduta que, mesmo se opondo à condução do modelo vigente, produziu muitas formas de se atuar na pesquisa em Etnomatemática sempre em relação à metanarrativa que constitui o campo do saber da Matemática acadêmica e não como a emergência de uma outra possibilidade de pensar e criar Matemática.

Desse modo, essa outra conduta que emerge na contramão da metanarrativa dominante no campo da Matemática, ainda mantém resíduos da formação discursiva que, pretensiosamente, pretende colocar a Matemática como única, universal e capaz de expressar verdades absolutas e, por isso, ainda acaba tornando-se modelo de referência para qualquer outro saber que queira ser focalizado numa perspectiva Etnomatemática. E, é nesse sentido residual que localizamos propostas e usos do termo Etnomatemática, ora como um procedimento metodológico para garantir o ensino da Matemática dominante, ora como uma proposta universalista e psicologizada que tem como foco responder à questão: $O$ que é Etnomatemática? E, o faz de forma simplista, procedimental e com viés de superação de um saber menor, à margem, à espera de uma redenção ou de reconhecimento pela comunidade acadêmica e escolar.

Ainda motivadas pelas palavras de Nietzsche, nosso interesse aqui é deslocar a pergunta: 
O que é a Etnomatemática? do contexto essencialista para propor uma discussão da Etnomatemática no campo das diferenças, das possibilidades. Deslocar esse grito para o campo filosófico, talvez como possibilidade de se criar um novo conceito, como prática de criação que só faz sentido diante de um problema a ser resolvido, como propõem Deleuze e Guatarri. Mas se perguntamos pelos problemas no campo da Etnomatemática, eles acontecem de formas diferentes, sempre vinculados aos usos e sentidos mobilizados nas distintas práticas culturais que são as geradoras da produção da pesquisa nessa área. Diante disso nos parece importante sempre indagar: quais as condições de produção do discurso da Etnomatemática no interior do campo da Matemática e da Educação; quais os efeitos produzidos por esses discursos no campo curricular; e quais possibilidades outras para se pensar essa proposta. Desse modo, questionarmos se poderíamos considerar esse grito como possibilidade de um novo conceito no sentido deleuziano. Questões essas que pretendemos lançar como disparadoras de um início e de continuidade de discussão.

\section{Referências}

APPLE, M.W. Conhecimento oficial. Petrópolis: Vozes, 1997.

BELLO, S. E. Jogos de linguagem, práticas discursivas e produção de verdade: contribuições para a educação (matemática) contemporânea. Zetetiké, Campinas, v.18, p.545-587, 2010.

CANDIOTTO, C. A governamentalidade política no pensamento de Foucault. Filosofia Unisinos, v.11, n.1, p.33-46, 2010.

CLARETO, S. M. Na travessia: construção de um campo problemático. In: CLARETO, S.M.; ROTONDO, M. A. S.; VEIGA, A. L. V. S. (Org.). Entre composições: formação, corpo e educação. 1.ed., Juiz de Fora: Editora da UFJF, 2011, p.17-32.

D’AMBRÓSIO, U. Etnomatemática um elo entre as tradições. Belo Horizonte: Autêntica, 2001.

DELEUZE, G.; GUATTARI, F. O que é a Filosofia? Rio de Janeiro: Ed. 34, 1992.

FOUCAULT, M. Segurança, território e população. São Paulo: Martins Fontes, 2008.

KNIJNIK, G. Exclusão e resistência: educação matemática e legitimidade cultural. Porto Alegre: Artes Médicas, 1996. 
MENDES, J. R. Ler, escrever e contar: práticas de numeramento-letramento dos Kaiabi no contexto de formação de professores índios do Parque Indígena do Xingu. 2001. 333f. Tese (Doutorado em Linguística Aplicada) - Instituto de Estudos da Linguagem, Universidade Estadual de Campinas, Campinas, 2001.

MENDES, J. R. Aspectos políticos e simbólicos na apropriação do discurso da Etnomatemática: o caso dos professores Kaiabi do Parque Indígena do Xingu. In: KNIJNIK, G., WANDERER, F.; OLIVEIRA, C. (Org.). Etnomatemática - currículo e formação de professores. Santa Cruz do Sul: EDUNISC, 2004, p.184-201.

MIGUEL, A., VILELA, D. S.; MOURA A. R. L. Desconstruindo a Matemática escolar sob uma perspectiva pós-metafísica da educação. Zetetiké, Campinas, v. 18, p.435-456, 2010.

MONTEIRO, A.; BROLEZZI, J. L. Escola um lugar de circulação de saberes: problematizando o currículo a partir de distintas práticas de medida de tempo. Leitura, Teoria \& Prática, v.30, p.518-526, 2012.

MONTEIRO, A. Etnomatemática: as possibilidades pedagógicas num curso de alfabetização para trabalhadores rurais assentados. 1998. 200f. Tese (Doutorado em Educação) - Faculdade de Educação, Universidade Estadual de Campinas, Campinas, 1998.

NIETZSCHE, F. A Gaia Ciência. São Paulo: Hemus, 1981.

ORELLANA R. C. A ética da resistência. Revista Ecopolítica, v.2, p.37-63, 2011.

SILVA, T. T.; MOREIRA, A. F. Territórios contestados. Rio de Janeiro, Vozes, 2001.

VEIGA-NETO, A. Governo ou governamento. Currículo sem Fronteiras, v.5, n.2, p.79-85, 2005.

VILELA D. S. Matemáticas nos usos e jogos de linguagem: ampliando concepções na educação matemática. 2010. 247f. Tese (Doutorado em Educação) - Faculdade de Educação, Universidade Estadual de Campinas, Campinas, 2010.

Recebido em dezembro de 2018. Aprovado em abril de 2019. 